\title{
Peer Effects in European Primary Schools: Evidence from the Progress in International Reading Literacy Study
}

\author{
Andreas Ammermueller, German Federal Ministry of \\ Labour and Social Affairs (BMAS) \\ Jörn-Steffen Pischke, London School of Economics
}

We estimate peer effects for fourth graders in six European countries. The identification relies on variation across classes within schools, which we argue are formed roughly randomly. The estimates are much reduced within schools compared to the standard ordinary least squares (OLS) results. This could be explained either by selection into schools or by measurement error in the peer variable. Correcting for measurement error, we find within-school estimates close to the original OLS estimates. Our results suggest that the peer effect is modestly large, measurement error is important in our survey data, and selection plays little role in biasing peer effects estimates.

\footnotetext{
We are grateful to Aaron Sojourner for extensive discussions on the relationship between his work and ours. We also thank Joshua Angrist, David Autor, PerAnders Edin, Edwin Leuven, Eric Maurin, Sandra McNally, Matt Pritsker, Kjell Salvanes, Jacob Vigdor, and Gylfi Zoega for helpful comments. Ammermueller gratefully acknowledges financial support from the Fritz Thyssen Foundation under the project "Bildungschancen zwischen Grundschule und Sekundarstufe" and would like to thank the Center for Economic Performance for its hospitality during his stay in London, during which the main work on this paper was completed. Contact the corresponding author, Jörn-Steffen Pischke, at s.pischke@ lse.ac.uk.
}

[Journal of Labor Economics, 2009, vol. 27, no. 3]

(C) 2009 by The University of Chicago. All rights reserved.

0734-306X/2009/2703-0005\$10.00 


\section{Introduction}

Learning in schools takes place in a group setting, and the composition of the group possibly affects individual outcomes. There has been a lot of interest in these types of social interactions in economics recently and in peer effects in school in particular. We revisit this issue in this paper, drawing on a previously unexploited data set in this context, the Progress in International Reading Literacy Study (PIRLS) for fourth graders. Our analysis covers six European countries: Germany, France, Iceland, the Netherlands, Norway, and Sweden.

One of the main challenges in the literature on peer effects is the feature that schools and classrooms are not formed randomly. School and class composition typically reflects neighborhood characteristics and therefore the family background of students. The estimated peer effect may capture unobserved aspects of an individual student's performance if this problem is ignored. We exploit the fact that the PIRLS survey samples multiple classrooms within a single school. This allows us to estimate peer effects within schools. Since we study students in primary schools, there is no explicit tracking in any of the countries in our sample. In Section IV we argue that classes within schools are in fact formed more or less randomly with respect to family background characteristics (other than immigrant status). The variation in our peer variable therefore most likely reflects that there will be small differences in composition when multiple groups are formed out of a small population (in essence the absence of the law of large numbers). Hence, our research design allows for a relatively credible identification of peer effects on student test scores.

The existing literature has used a wide variety of approaches to identify peer effects. The papers closest in spirit to ours are the ones by Hoxby (2000) and Vigdor and Nechyba (2004) for the United States and Gould, Lavy, and Paserman (forthcoming) for Israel. These papers similarly rely on differences in the compositions of individual classes within a school, which come about by chance. Hanushek et al. (2003) and McEwan (2003) also use within-school variation to identify peer effects. However, it is more difficult to believe that differences in class composition are random in their cases. We will compare our methodology in detail to the existing literature in the next section. A number of recent studies have also used explicit random assignment to classes or schools or other natural experiments. However, none of these studies pertain to European countries.

An important issue in our context is the fact that our peer measure is self-reported by the students' parents and that the sample does not include all students in a classroom. These features will lead to measurement error in both the individual- and peer-level variables in the regression and hence to biased estimates. Moreover, the size of the bias will differ in the ordinary least squares (OLS) and within-school estimates. We address these issues 
in Section VI in two ways. The first is to use an alternative variable for family background as an instrument. The second is to look at the ratio of the peer- and individual-level family background effects. We show that the within-school estimator for this ratio is not affected by measurement error under a simple measurement error model. Nevertheless, even this estimator is biased when not all students in a class are sampled. We adjust our estimates for the sampling error in the peer variable arising from missing students. Clarifying the impact of measurement error on estimates of peer effects is an important contribution of our paper. The only other paper in the literature dealing with missing observations in peers' models is concurrent work by Sojourner (2008). His analysis complements ours since he allows for more general processes generating missing students, but he does not analyze measurement error explicitly.

On average across countries, we find that a one-standard-deviation change in our measure of peer composition leads to a 0.17 -standarddeviation change in reading test scores, and this estimate is marginally significant. The size of this effect is slightly larger than most estimates reported in the literature. However, the confidence interval for our measurement error corrected estimate is fairly large. Moreover, the pattern of our results is largely consistent with a story based purely on measurement error, but systematic selection into schools by family background seems to play little role.

\section{Empirical Framework and Existing Literature}

As in many peer effects studies, we start from a reduced-form specification of an education production function of the form

$$
y_{i c s}=\alpha_{s}+\beta X_{i c s}+\gamma S_{c s}+\lambda \bar{X}_{(-i) c s}+\mu_{c s}+\epsilon_{i c s},
$$

where $y_{i c s}$ is a student outcome, such as a test score, for student $i$ in classroom $c$ and school $s ; X_{i c s}$ are student or family characteristics, such as sex, family background, and so forth; $S_{c s}$ are school- or class-level characteristics, such as class size, teacher experience, characteristics of the municipality, and so forth; and $\bar{X}_{(-i) c s}$ are the average characteristics of the peers of student $i$. In addition, $\mu_{c s}$ and $\epsilon_{i c s}$ are, respectively, class-level and individual-level error terms. The reduced form is silent on how the peer effect arises. In the language of Manski (1993), $\lambda$ could capture either exogenous (or contextual) or endogenous effects. Exogenous effects arise when individuals learn more because the group of peers is more favorable in terms of their predetermined characteristics. Endogenous effects arise when individuals learn more because peers are learning more. We make no attempt at separating these.

The term $\mu_{c s}$ reflects correlated effects. Correlated effects arise when the group of peers is subject to a common influence, which is not modeled 
directly. These effects will give rise to a bias if they are correlated with peer group composition. For example, consider a remedial classroom with relatively poorly performing children. This classroom may be assigned a particularly able teacher, but the exceptional characteristics of this teacher are not observable. Removing the potential bias from correlated effects is one of the main challenges in the peer effects literature.

If some relevant school or classroom characteristics are not controlled, the estimated peer effect $\hat{\lambda}$ will be biased. Random assignment of students and teachers to classrooms solves this problem because random assignment breaks the link between peer characteristics and extraneous effects on the class, like unobserved teacher quality. Boozer and Cacciola (2001) and Graham (2008) exploit the random assignment in the Tennessee Student/Teacher Achievement Ratio (STAR) experiment on class size. Cullen, Jacob, and Levitt (2006) use lotteries at oversubscribed Chicago public schools. However, their paper does not focus on the issue of peer effects.

True random assignment variation is rare in an education context and unavailable in many countries. Hence, researchers have to resort to other strategies utilizing the existing data. In this paper, as in a variety of related studies, we use variation within schools in order to identify the peer effect. This means that we include school fixed effects, $\alpha_{s}$, in our regression (1). ${ }^{1}$

The idea behind this strategy is the observation that different schools draw students from different neighborhoods and hence family backgrounds. Hence, the unobserved characteristics $\mu_{c s}$ will be systematically related to $\bar{X}_{(-i) c s}$ at the school level. However, students are not generally grouped into classes on the basis of ability or family background in primary school. Although some countries, such as Germany, track students into a rigid system of separate schools at the secondary level, there is no systemwide tracking at the primary level. In fact, classes in primary schools with multiple classrooms at the same grade level are typically formed more or less on a random basis. In this case, $\bar{X}_{(-i) c s}$ will be uncorrelated with the class-level shocks $\mu_{c s}$ conditional on a set of school fixed effects or the characteristics of school peers. The bias from correlated effects is thus removed, and $\lambda$ can be estimated consistently.

In order to make this argument more precise, consider the following simple model generating student characteristics:

$$
X_{i c s}=\eta_{c s}+v_{i c s} ;
$$

that is, student characteristics consist of a common classroom-level mean

${ }^{1}$ Alternatively, we could introduce peer variables at the school level directly into the estimating equation. Both approaches lead to very similar results. 
$\eta_{c s}$ and an idiosyncratic, mean zero student-level component $v_{i c s}$, which is uncorrelated with $\eta_{c s}$ and $\epsilon_{i c s}$. The peer mean is

$$
\bar{X}_{(-i) c s}=\eta_{c s}+\bar{v}_{(-i) c s} .
$$

Correlated effects arise whenever $\operatorname{Cov}\left(\eta_{c s}, \mu_{c s}\right) \neq 0$. Estimates of both $\beta$ and $\lambda$ will therefore be biased in the estimation of equation (1). Our basic identifying assumption is $\eta_{c s}=\eta_{s}$; that is, the systematic component of the student background characteristic arises only at the school level but not at the class level. Random assignment of students and resources to classes within schools would ensure that this condition is met. Let the operator $\tilde{\Delta}$ perform the within transformation, so that $\tilde{\Delta} a_{i c s}=a_{i c s}-\bar{a}_{s}$. Hence, peer characteristics within schools are $\tilde{\Delta} \bar{X}_{(-i) c s}=\tilde{\Delta} \bar{v}_{(-i) c s}$; that is, variation in the peer measure comes only from the fact that $\bar{v}_{(-i) c s} \neq 0$ in small groups. A necessary condition for the within-school estimation to work is, of course, that there is sufficient variance in peer composition of a classroom within a school, which is the case in our data; see Section III below.

Our identification strategy is most closely related to that of McEwan (2003) and Vigdor and Nechyba $(2004,2006)$. McEwan studies peer effects for eighth graders in Chile. However, random assignment to classes within schools is much less likely to happen at the secondary level because schools in many countries, including Chile, track students to at least some degree. If there is tracking on the basis of (unobserved) ability, estimates of $\lambda$ are still confounded by correlated effects. Vigdor and Nechyba (2004) also rely on school fixed effects for identification. Their results are for fifth graders in North Carolina, an age group for which tracking is less of an issue. However, they report evidence that classroom assignment does not look random in most schools. Hence, in their preferred estimates, they restrict themselves to a subsample of schools for which classroom assignment looks random on the basis of preliminary tests. However, this pretesting approach is not completely satisfying. In this paper, in contrast, we argue that classroom assignment is random in European schools for institutional reasons, and we successfully verify this claim with tests similar to those employed by Vigdor and Nechyba (2004).

The papers by Clotfelter, Ladd, and Vigdor (2006) and Vigdor and Nechyba (2006) cast some doubt on their main identifying assumption of random classroom assignment within schools. Using the same data for North Carolina elementary schools, Clotfelter et al. present some evidence that better teachers are assigned to classrooms with better students, even within schools. This may be due to "teacher shopping" by parents or to the ability of better teachers to avoid assignment to classes with more poorly performing students. 
In an alternative approach, Vigdor and Nechyba (2006) find positive and significant peer effects in models with school fixed effects. They then go and introduce teacher fixed effects, hence comparing successive cohorts of students assigned to the same teacher. The introduction of teacher fixed effects in addition to school fixed effects leads to significantly negative estimates of peer effects. This suggests that random assignment of students to classrooms does not seem to be satisfied in the North Carolina context, and their results cast some doubt on their own earlier findings (Vigdor and Nechyba 2004). We are less worried about their findings for the case of European primary schools because we believe that the practice of teacher shopping or the purposeful assignment of good teachers to better classes is absent or comparatively unimportant in the countries we analyze.

Hoxby (2000), Hanushek et al. (2003), and Gould et al. (forthcoming) also use within-school variation to identify peer effects. The Hoxby and Gould et al. studies are similar in spirit to ours. We use comparisons across classrooms within the same grade for the same cohort of students. Hoxby uses comparisons between classes in the same grade across adjacent cohorts and years. Hence, she identifies peer effects from variation arising from the composition of subsequent cohorts. For example, one cohort may have more girls and the next cohort fewer for purely random reasons. Gould et al. also use data on multiple cohorts in the same grade. They condition on the student composition of the grade across multiple cohorts of students. Effectively, like Hoxby, they therefore exploit year-to-year variation in the composition of successive cohorts of students. However, these studies tend to focus on peer group measures different from ours. Hoxby looks at gender and race composition of the classroom and performance by opposite gender and race groups, whereas Gould et al. look at the share of immigrants.

Hanushek et al. (2003) focus on a peer measure more similar to ours. They also control for school by grade effects like Hoxby and Gould et al. However, they track the same cohort of students over time, rather than different cohorts, and they also control for student fixed effects. This means that they effectively consider only changes in the peer group that come about through changes in a student's classroom assignment over time and not changes in cohort composition, as in the Hoxby and Gould et al. studies. Including student fixed effects should exacerbate any problems from the nonrandom assignment of teachers to classrooms highlighted by Clotfelter et al. (2006). Hence, controlling for student fixed effects may lead to a larger upward bias in the estimates when there is teacher shopping. In fact, Hanushek et al. find an increase in the peer coefficient when they control for individual student effects compared to a similar specification without individual effects.

The previous literature finds peer effects that range from close to zero (Cullen et al. 2006) to about 0.5 for a one-standard-deviation change in 
the peer measure (Hoxby 2000; Boozer and Cacciola 2001). The results of many other studies fall within this range but are clustered around the bottom end.

\section{Data and Descriptive Statistics}

Thirty-five countries participated in the Progress in International Reading Literacy Study. This study was conducted by the International Association for the Evaluation of Educational Achievement (IEA) in 2001 by testing 9- and 10-year-olds in reading literacy. Extensive information on home and school environment is available from student, parent, teacher, and school questionnaires. With 150,000 students tested, PIRLS 2001 is the first in a planned 5-year cycle of international trend studies in reading literacy (Mullis et al. 2003).

The data are collected in a two-stage stratified sampling design. First, participating schools were chosen. Therefore, the schools are the primary sampling units, not the classes or students. Within each school, a sample of classes from the targeted grade was drawn. The targeted grade is the upper of the two grades with the most 9-year-olds at the time of testing. This is always the fourth grade in our sample of countries. Within each class, in principle, all students are sampled. In practice, the number of sampled students can be smaller than the actual class size because of student nonparticipation. We use all European countries with a sufficient number of schools with at least two classes. These are France, Germany, Iceland, the Netherlands, Norway, and Sweden.

Student performance is measured by test scores in reading literacy, which Campbell et al. $(2001,1)$ describe as "one of the most important abilities students acquire as they progress through their early school years. It is the foundation for learning across all subjects." The test scores are plausible values that are drawn from an estimated proficiency distribution. Plausible values are imputed scores based on the students' answers to the test items (cf. Mislevy 1991). The scores have then been standardized to an international mean of 500 and a standard deviation of 100, which facilitates the comparison across countries. The reliability of the PIRLS testing instrument across 10 versions of the test ranges from 0.83 to 0.89 in our sample countries (Mullis et al. 2003).

Table 1 provides information on mean reading scores and sample sizes in PIRLS at the student, class, and school levels. Students, classes, and schools can be directly identified. Missing values of student background, class, and school variables are a serious problem in the data set. For parents' education, $36 \%$ of all values are missing. Instead of parents' education, we use the number of books at home as our indicator of family background. Among the variables reflecting family background, this is the one with the best item response rate. In addition, this is an appealing 
Table 1

Mean Reading Scores and Sample Sizes

\begin{tabular}{|c|c|c|c|c|c|c|}
\hline & Germany & France & Iceland & Netherlands & Norway & Sweden \\
\hline \multicolumn{7}{|l|}{ Reading score: } \\
\hline All & $\begin{array}{l}539.1 \\
(63.6)\end{array}$ & $\begin{array}{l}525.2 \\
(66.6)\end{array}$ & $\begin{array}{l}512.4 \\
(71.0)\end{array}$ & $\begin{array}{l}554.2 \\
(51.2)\end{array}$ & $\begin{array}{l}499.2 \\
(77.5)\end{array}$ & $\begin{array}{l}561.0 \\
(61.5)\end{array}$ \\
\hline Sample & $\begin{array}{l}548.6 \\
(59.9)\end{array}$ & $\begin{array}{l}533.7 \\
(64.2)\end{array}$ & $\begin{array}{l}518.6 \\
(68.4)\end{array}$ & $\begin{array}{l}565.2 \\
(51.3)\end{array}$ & $\begin{array}{l}505.0 \\
(76.0)\end{array}$ & $\begin{array}{l}563.1 \\
(61.3)\end{array}$ \\
\hline Excluding tracked & & & & & & \\
\hline schools & $\begin{array}{l}548.6 \\
(59.7)\end{array}$ & $\begin{array}{l}534.2 \\
(65.4)\end{array}$ & $\begin{array}{l}518.7 \\
(68.3)\end{array}$ & $\begin{array}{l}562.8 \\
(53.6)\end{array}$ & $\begin{array}{l}504.4 \\
(76.4)\end{array}$ & $\begin{array}{l}562.8 \\
(61.5)\end{array}$ \\
\hline Tracked schools & $\begin{array}{l}549.4 \\
(64.2)\end{array}$ & $\begin{array}{l}532.2 \\
(60.5)\end{array}$ & $\begin{array}{l}506.8 \\
(81.0)\end{array}$ & $\begin{array}{l}568.8 \\
(47.5)\end{array}$ & $\begin{array}{l}529.1 \\
(66.5)\end{array}$ & $\begin{array}{l}570.0 \\
(56.6)\end{array}$ \\
\hline \multicolumn{7}{|l|}{ Number of students: } \\
\hline All & 7,633 & 3,538 & 3,676 & 4,112 & 3,459 & 6,044 \\
\hline Sample & 4,577 & 2,312 & 1,728 & 1,857 & 2,548 & 3,997 \\
\hline $\begin{array}{l}\text { In schools with > } \\
1 \text { class }\end{array}$ & 3,628 & 1,612 & 1,301 & , & 1,748 & 3,270 \\
\hline Number of schools & 183 & 115 & 84 & 105 & 117 & 119 \\
\hline $\begin{array}{c}\text { Number of schools } \\
\text { with }>1 \text { class }\end{array}$ & 114 & 55 & 39 & 29 & 54 & 79 \\
\hline Number of classes & 301 & 172 & 135 & 141 & 171 & 267 \\
\hline $\begin{array}{l}\text { Number of classes } \\
\text { in schools with > } \\
1 \text { class } \\
\text { Fraction of students }\end{array}$ & 232 & 112 & 90 & 65 & 108 & 227 \\
\hline $\begin{array}{l}\text { Fraction of students } \\
\text { in schools that ap- } \\
\text { ply tracking }\end{array}$ & .067 & .278 & .006 & .328 & .035 & .046 \\
\hline
\end{tabular}

Note.-Scores are weighted by students' sampling probability; standard deviations are in parentheses. The rows starting from "number of students: sample" and below refer to the sample used in the estimations. The last row reports the fraction of students in schools in which principals state that classes are formed by ability out of all students in schools for which principals reply to the question.

variable in its own right. It is highly correlated with parental income, education, and origin. The variable also reflects whether the parents value literary skills. Parents who own many books most likely will also promote reading among their children. In fact, Wößmann (2008) found the number of books to be the single most important predictor of reading skills among various family background variables in the Third International Math and Science Study and Ammermueller (2005) in PIRLS and the Programme for International Student Assessment (PISA) data. Another advantage of the books at home variable is that it is asked of both parents and students, allowing us to use instrumental variable (IV) estimation in order to address potential measurement error in the variable.

Table 1 demonstrates that the sample size, conditioning on nonmissing student background and school variables, shrinks to about $40 \%-75 \%$ of the original. The row labeled "number of students: sample" gives the sizes of the samples we actually use. All figures in this row and below refer to the sample with no missing values. Reading scores in the selected samples are slightly higher than in the overall sample, as can be seen in the first two rows in the table. Some sample schools have only one class. 
Our within-school estimates will be utilizing only the schools with two or more classes. Information on the students, classes, and schools with more than one class can be found in the bottom rows of table 1 . The peer effects estimations have also been performed including all observations for which test scores are reported. Missing values have been replaced by zeros, and dummy variables for missing values for each variable have been added to the regressions. The estimated peer effects are comparable to the results presented below.

The home questionnaire asked parents to report the number of books in their home in five categories: none or few books (0-10), enough to fill one shelf (11-25), enough to fill one bookcase (26-100), enough to fill two bookcases (101-200), and enough to fill three or more bookcases (more than 200). ${ }^{2}$ In order to form a single measure of students' background, after some experimentation, we chose a simple index that assigns 1 to the lowest category $(0-10)$ and 5 to the highest category (more than 200). The median parent reports $26-100$ or 101-200 books, and the means of the indices range from about 3.3 to 4 , depending on the country (see table 2 below).

We generated peer variables as the class average of five student background variables: number of books at home, student's sex and age, whether at least one parent was born abroad, and whether a foreign language is spoken at home. There is a discussion in the literature on peer effects whether classrooms or schools (or possibly even neighborhoods) are the more appropriate unit of peer interactions. Of course, peer interactions may occur at each of these levels, and it is an open question which is the most important. We focus on the classroom level for the pragmatic reason that we want to analyze differences within schools. In the within-school estimates, all peer interactions with students from other classes in the school will be absorbed into the school fixed effects. However, peer effects in the classroom are clearly of interest for academic outcomes, since classes are the basic unit where learning takes place. It is therefore natural to expect that a large fraction of total peer effects should arise at the classroom level.

The peer averages are formed using information for all students who report a value for this specific variable in the data set, not just the students in the final sample. In table 2, we decompose the total variance in these class averages into the parts of the variance within and between schools using the relationship

$$
\frac{1}{C} \sum_{s=1}^{S} \sum_{c=1}^{C_{s}}\left(x_{c s}-\bar{x}\right)^{2}=\frac{1}{C} \sum_{s=1}^{S} \sum_{c=1}^{C_{s}}\left(x_{c s}-\bar{x}_{s}\right)^{2}+\frac{1}{C} \sum_{s=1}^{S} C_{s}\left(\bar{x}_{s}-\bar{x}\right)^{2}
$$

${ }^{2}$ Using instead the number of books at home reported by students yields comparable results. 
Table 2

Decomposition of Variance in Class-Level Means

\begin{tabular}{|c|c|c|c|c|c|c|}
\hline & Germany & France & Iceland & Netherlands & Norway & Sweden \\
\hline \multicolumn{7}{|c|}{$\begin{array}{c}\text { Index of the number of } \\
\text { books at home: }\end{array}$} \\
\hline Mean & 3.49 & 3.32 & 3.99 & 3.36 & 4.03 & 3.91 \\
\hline Total & .2401 & .3138 & .1480 & .3922 & .1542 & .2643 \\
\hline Between & .2098 & .2726 & .1220 & .3629 & .1297 & .2174 \\
\hline Within & .0303 & .0412 & .0259 & .0293 & .0245 & .0469 \\
\hline \multicolumn{7}{|l|}{ Age: } \\
\hline Total & .0326 & .0313 & .0065 & .0306 & .0082 & .0111 \\
\hline Between & .0250 & .0183 & .0050 & .0212 & .0060 & .0060 \\
\hline Within & .0076 & .0130 & .0015 & .0094 & .0022 & .0051 \\
\hline \multicolumn{7}{|l|}{ Female: } \\
\hline Total & .0145 & .0226 & .0212 & .0156 & .0145 & .0158 \\
\hline Between & .0085 & .0174 & .0170 & .0139 & .0125 & .0091 \\
\hline Within & .0061 & .0052 & .0043 & .0017 & .0020 & .0067 \\
\hline \multicolumn{7}{|c|}{ Foreign parent: } \\
\hline Total & .0459 & .0463 & .0095 & .0488 & .0222 & .0485 \\
\hline Between & .0404 & .0413 & .0069 & .0451 & .0189 & .0386 \\
\hline Within & .0054 & .0050 & .0026 & .0036 & .0033 & .0099 \\
\hline \multicolumn{7}{|c|}{$\begin{array}{l}\text { Foreign language at } \\
\text { home: }\end{array}$} \\
\hline Total & .0141 & .0151 & .0088 & .0345 & .0069 & .0230 \\
\hline Between & .0112 & .0128 & .0058 & .0330 & .0052 & .0167 \\
\hline Within & .0029 & .0023 & .0030 & .0015 & .0017 & .0064 \\
\hline \multicolumn{7}{|c|}{ Reading test scores: } \\
\hline Total & $1,144.71$ & $1,223.61$ & 751.93 & 896.62 & $1,075.93$ & $1,123.78$ \\
\hline Between & 978.47 & 908.63 & 569.62 & 799.28 & 933.10 & 791.51 \\
\hline Within & 166.24 & 314.97 & 182.31 & 97.34 & 142.83 & 332.27 \\
\hline
\end{tabular}

where $x$ is the specific variable we are interested in, $s=1,2, \ldots, S$ is a school indicator, $c=1,2, \ldots, C_{S}$ is a class indicator, and there are $C_{S}$ classes in school $s$. The variable $C$ is the total number of classes across all schools in our sample. ${ }^{3}$

Table 2 presents the total, between-, and within-school variance of the peer variables. The variation for the average reading test score is shown as well. It is obvious that most of the variance in all these measures is between schools. ${ }^{4}$ Between $7 \%$ and $18 \%$ of the variance in the index for the number of books at home is within schools. The fraction is higher for the reading test scores. However, $70 \%$ or more of the peer variation in test scores is also between schools. This suggests that a large part of the variation in all these measures is accounted for by school effects.

${ }^{3}$ For the variance decomposition to add to the total variance in an unbalanced panel, it is necessary to weight the between component by the number of classes in the sample. This is not what, e.g., the Stata xtsum command calculates.

${ }^{4}$ The reader thinking of individual-level variation in student performance may be surprised by this. Most student-level variation is within schools. However, most of this variation is also within classrooms, and we consider the variation in classroom means here. 
Nevertheless, there is also some nonnegligible amount of variance left within schools.

\section{Selection in Classroom Formation}

In this section we will discuss the assignment of students both between and within schools. We start by presenting some basic information on primary schooling in the countries we study. We then go on to present some evidence from the PIRLS data to shed light on the question whether classes are formed (more or less) randomly and whether different classrooms systematically get different resources.

In all six countries in our sample, students attend a single-tracked primary school from school enrollment to at least grade 4, in which students have been tested in PIRLS. ${ }^{5}$ While students are assigned to various school types after grade 4 in Germany, they stay on for at least 2 more years in primary school in most other countries (France, Iceland, the Netherlands, and Sweden) or go on to a single-tracked secondary school (Norway). School choice at the primary level is unrestricted in some countries (Germany and the Netherlands), whereas school assignment depends on the place of residence in the other countries. However, parents have some means to influence the choice of schools also in these countries. In practice, most parents choose the nearest school for convenience in all countries (or live near the school of their choice). The heads of the school are responsible for the assignment of students to classes within schools. Most countries have legal rules on maximum class size, and some school systems provide extra resources for schools with a high share of immigrant students. The final responsibility in assigning students to classrooms lies with the heads of the schools, however. Grouping of students seems to happen in some cases on the basis of the migration background of students. Most of our sample countries do not use any explicit grouping of students by ability in primary school. The Netherlands and Sweden have the most decentralized systems, and schools are relatively free to decide how to form classes. In practice, students are mostly grouped by age in the Netherlands, although classes are sometimes formed by proficiency across age groups. In Sweden, class groups may not be fixed, and ability grouping might happen for short periods of time (Mullis et al. 2002). For Iceland, the Compulsory Schools Act of 1995 states explicitly that there is no selection or streaming by ability of students. ${ }^{6}$

In order to corroborate that these institutional descriptions translate into more or less random assignment of students to classes, we conducted

\footnotetext{
${ }^{5}$ The information on the schooling systems is taken from Eurybase, the database in the information network on education in Europe (http://www.eurydice.org).

${ }^{6}$ We consulted researchers in each of the sample countries, and they also confirmed the impression that ability grouping would be rare.
} 
Table 3

Results for Survey of Principals of German Primary Schools

\begin{tabular}{|c|c|}
\hline Question & $\begin{array}{l}\text { Response } \\
(\%)\end{array}$ \\
\hline \multicolumn{2}{|l|}{$\begin{array}{l}\text { Who is responsible for forming classrooms/allocating students to classes } \\
\text { within a grade level at your school? }\end{array}$} \\
\hline Principal & 86 \\
\hline Other person & 42 \\
\hline \multicolumn{2}{|l|}{$\begin{array}{l}\text { Does the composition of classes change during the first } 4 \text { years of } \\
\text { school? }\end{array}$} \\
\hline No, usually not & 75 \\
\hline Yes, class composition is rearranged in certain years & 8 \\
\hline $\begin{array}{l}\text { Yes, individual students change classes for reasons other than } \\
\text { repeating }\end{array}$ & 22 \\
\hline Only under particular circumstances & 39 \\
\hline \multicolumn{2}{|l|}{$\begin{array}{l}\text { Which are the rules for forming classes/allocating students to classes in } \\
\text { your primary school? }\end{array}$} \\
\hline Classes are formed such that similar students are in the same class: & \\
\hline Students from the same neighborhood/kindergarten & 33 \\
\hline Students with similar abilities & 6 \\
\hline Students with similar socioeconomic backgrounds & 3 \\
\hline Students with similar migration backgrounds/language abilities & 3 \\
\hline $\begin{array}{l}\text { Classes are formed such that they are well mixed (e.g., by sex, age, } \\
\text { abilities, etc.) }\end{array}$ & 94 \\
\hline Classes are formed more or less randomly & 0 \\
\hline Classes are formed according to other rules/principles & 3 \\
\hline
\end{tabular}

a small survey by e-mail among heads of primary schools in Germany. The results in table 3 confirm that heads of schools are primarily responsible for forming classrooms, often together with a teacher. The composition of classes does not usually change during the first 4 years of school for three-quarters of all respondents. Classes are rearranged mostly because of a large number of newly arriving students. Individual students who are disruptive in their current class may be allocated to other classes by the head of the school. Additional information from openended responses provides no indication that students change classes on their behalf or for other forms of "teacher shopping." Classes are actually mostly formed so that they are well balanced (94\%). Students from the same neighborhood or kindergarten are put in the same class in a third of all schools. Only $6 \%$ of schools mention grouping students of similar abilities.

The PIRLS data also asked in the schools questionnaire whether the school forms sample classes on the basis of ability. The last row in table 1 reports the fraction of students in schools that report some ability grouping at the class level. This fraction is very low except in France and the Netherlands, where it reaches on the order of $30 \%$. While we do not find much evidence that the classes in these tracked schools look very 
different from classes in other schools, we also show results excluding those schools that report some tracking.

We investigate two separate and distinct questions about classroom formation with the PIRLS data. The first, and most important, question is whether classes within schools are being formed randomly. The second question is whether classrooms that differ in composition, for random or nonrandom reasons, receive different resources.

In order to test whether classrooms are formed randomly with respect to a particular student characteristic, we perform a series of Pearson $\chi^{2}$ tests. If classes are formed randomly, the student characteristic under study and the class the student is assigned to should be statistically independent. Consider student sex, for example. The Pearson $\chi^{2}$ test asks whether there are more females in a particular class than is consistent with independence, given the number of students in the school. Formally, for each school the test statistic is given by

$$
P=\sum_{c} \sum_{j} \frac{\left(n_{c j}-\hat{n}_{c j}\right)^{2}}{\hat{n}_{c j}}
$$

where $n_{c j}$ is the number of students with characteristic $j=1, \ldots, J$ in classroom $c=1, \ldots, C_{s}$. Define

$$
n_{c \cdot}=\sum_{j} n_{c j}, \quad n_{\cdot j}=\sum_{c} n_{c j}, \quad \hat{n}_{c j}=\frac{n_{c \cdot} \cdot n_{\cdot j}}{\sum_{c} \sum_{j} n_{c j}}
$$

where $\hat{n}_{c j}$ is the predicted number of students with characteristic $j$ in classroom $c$ when characteristic and classroom are independent. Then, under the null hypothesis of independence, $P \sim \chi^{2}$ with $\left(C_{S}-1\right)(J-1)$ degrees of freedom.

We further assume that the $S$ schools in a country are independent. In this case, we can simply add up the $S$ test statistics to get an aggregate test statistic with $\left[\sum\left(C_{s}-1\right)\right](J-1)$ degrees of freedom (see, e.g., DeGroot 1984, 384). Obviously, the test can be carried out only on the subsample of schools with two or more classrooms. We found in a small Monte Carlo experiment that the test generally performs well, although it rejects somewhat too often under the null. The empirical rejection rate for a $5 \%$ nominal size is about 0.13 . However, the test seems to have good power.

Table 4 presents the $p$-values for these tests in the first row of each panel for various different student characteristics. The $p$-values for books at home are well above the $5 \%$ level except for Sweden, where the $p$ value is 0.036 (we find such a $p$-value about $10 \%$ of the time in the simulations under the null). We also find evidence of nonrandom assign-

\footnotetext{
${ }^{7}$ Details on the simulation study are available from the authors on request.
} 
Table 4

Tests for Independence of Peer Variable and Class Assignment and for Assignment of Classroom Resources

\begin{tabular}{|c|c|c|c|c|c|c|}
\hline & Germany & France & Iceland & Netherlands & Norway & Sweden \\
\hline \multicolumn{7}{|c|}{$\begin{array}{c}\text { Index of the number of } \\
\text { books at home: }\end{array}$} \\
\hline Pearson $\chi^{2}$ & .2415 & .3813 & .7964 & .7512 & .0893 & .0364 \\
\hline$F$-test & .4595 & .2552 & .0123 & .3370 & .5675 & .0000 \\
\hline \multicolumn{7}{|l|}{ Age: } \\
\hline $\begin{array}{l}\text { Pearson } \chi^{2} \\
F \text {-test }\end{array}$ & $\begin{array}{l}.0694 \\
.0017\end{array}$ & $\begin{array}{l}.2402 \\
.2672\end{array}$ & $\begin{array}{l}.1452 \\
.0021\end{array}$ & $\begin{array}{l}.0992 \\
.0046\end{array}$ & $\begin{array}{l}.0467 \\
.0000\end{array}$ & $\begin{array}{l}.6247 \\
.9300\end{array}$ \\
\hline \multicolumn{7}{|l|}{ Female: } \\
\hline Pearson $\chi^{2}$ & .1240 & .4615 & .9608 & .6011 & .8827 & .9657 \\
\hline$F$-test & .5677 & .2838 & .0000 & .1467 & .0036 & .1589 \\
\hline \multicolumn{7}{|c|}{$\begin{array}{l}\text { Foreign language at } \\
\text { home: }\end{array}$} \\
\hline Pearson $\chi^{2}$ & .0495 & .6920 & .1861 & .4217 & .4860 & .0009 \\
\hline$F$-test & .0000 & .4776 & .0001 & .0000 & .0029 & .0000 \\
\hline
\end{tabular}

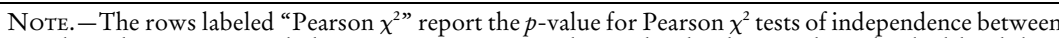
the student characteristic and classroom assignment within each school using the individual-level data. The rows labeled " $F$-test" report $p$-values of Wald tests for the joint significance of classroom resources in within-school regressions. See the text for details.

ment of nonnative-language children for Sweden and possibly Germany. Recall that principals in a significant number of schools in France and the Netherlands report ability grouping in their schools. The $p$-values differ only slightly when we split the sample between the schools that report tracking in France and the Netherlands and those that do not. One exception is the evidence for sorting by age within the 19 schools that may be tracked in France. Overall, we conclude that there is little evidence of systematic formation of classrooms, particularly with respect to our family background measure books at home. Sweden might be the only exception.

Even if classrooms are formed randomly, they may still differ in systematic ways because school resources also have to be distributed to classes. The assignment of classroom resources may not be random, even if classes are formed randomly. For example, a class may end up with more children from less advantaged family backgrounds purely by chance, and the school might assign this class a better (or a worse) teacher. Our estimates of the peer effects would be biased if this happened systematically across schools.

In order to shed light on this question, we ran a set of regressions of the peer variables described in the previous section on classroom and teacher characteristics. The observable characteristics of classrooms are class size and its square, teacher gender, education, experience, and its square. Table 4 shows $p$-values for the corresponding $F$-tests on the joint significance of these variables from a regression including school fixed effects in the second row of each panel. For our family background var- 
iable of interest, the number of books at home, the class variables are insignificant except in Iceland and in Sweden. In the case of Iceland, it turns out that this correlation is solely driven by a single classroom with a teacher with 20 years of experience (all other teachers in Iceland have 10 or fewer years of experience). We discount this result as spurious. In the case of Sweden this seems indeed to indicate a nonrandom allocation of classroom resources to classes with students from different backgrounds, even within schools. In particular, there is evidence that class size increases with average background of students in a class. The coefficients for the other class and school variables are not significant.

We also find some evidence that classrooms differ for students by age (in Germany, Iceland, and Norway) and by student sex (in Iceland, the Netherlands, and Norway). It also seems fairly clear that classes are different for students not speaking the native language at home in most of our sample countries. The higher the share of immigrant students in a class, the lower teacher's education in Germany and Norway. In Sweden, there is weak evidence of an allocation of immigrant students to larger classes.

Our results largely confirm that classes in the sample countries seem to be formed roughly randomly within schools. There is little evidence that students of different family backgrounds are more likely to be grouped in certain classes conditional on the school they attend or that classes with different compositions receive different (observable) resources. This is comforting for our analysis. The only country for which this does not seem to be the case is Sweden. Hence, the Swedish results may have to be taken with a grain more of salt. But the Swedish results turn out to be very close to the average of the other countries, so this does not seem to matter for our findings in practice. In addition, immigrant children, which are an important group in all the sample countries, also seem to be nonrandomly assigned and given different teaching resources. Nevertheless, we do not find any evidence that the nonrandom sorting of immigrant children to classes affects our results on the books at home variable.

\section{Basic Results on Peer Effects}

We now turn to our results on peer effects. Table 5 summarizes the results for the six countries. Our family background and peers variable, books at home, takes on five values. The most flexible way to use this variable is to create a set of four dummy variables and, correspondingly, the fraction of peers in these four categories. Since this leads to a large number of coefficients and given that the coefficient estimates are roughly monotonically increasing in the categories, we have chosen to simply create an index taking on the values $1-5$, which we created from these 
Table 5

Regressions for Reading Test Score on Peer Composition

\begin{tabular}{|c|c|c|c|c|c|}
\hline Country & (1) & (2) & (3) & (4) & (5) \\
\hline Germany & $\begin{array}{l}17.97 \\
(3.04)\end{array}$ & $\begin{array}{l}17.66 \\
(3.03)\end{array}$ & $\begin{array}{l}18.83 \\
(3.83)\end{array}$ & $\begin{array}{c}6.13 \\
(6.24)\end{array}$ & $\begin{array}{c}7.22 \\
(6.40)\end{array}$ \\
\hline France & $\begin{array}{c}22.23 \\
(3.05)\end{array}$ & $\begin{array}{c}22.84 \\
(2.91)\end{array}$ & $\begin{array}{l}25.67 \\
(3.94)\end{array}$ & $\begin{array}{c}22.20 \\
(9.12)\end{array}$ & $\begin{array}{c}17.80 \\
(12.58)\end{array}$ \\
\hline Iceland & $\begin{array}{l}18.08 \\
(5.77)\end{array}$ & $\begin{array}{l}19.97 \\
(5.04)\end{array}$ & $\begin{array}{l}22.75 \\
(5.58)\end{array}$ & $\begin{array}{c}12.14 \\
(11.17)\end{array}$ & $\begin{array}{c}8.81 \\
(11.18)\end{array}$ \\
\hline Netherlands & $\begin{array}{l}17.58 \\
(4.30)\end{array}$ & $\begin{array}{l}19.70 \\
(4.37)\end{array}$ & $\begin{array}{l}22.72 \\
(6.99)\end{array}$ & $\begin{array}{c}.71 \\
(8.59)\end{array}$ & $\begin{array}{c}9.56 \\
(9.93)\end{array}$ \\
\hline Norway & $\begin{array}{l}15.46 \\
(7.33)\end{array}$ & $\begin{array}{c}9.84 \\
(7.42)\end{array}$ & $\begin{array}{l}12.73 \\
(7.85)\end{array}$ & $\begin{array}{c}-3.20 \\
(8.13)\end{array}$ & $\begin{array}{c}-2.77 \\
(8.24)\end{array}$ \\
\hline Sweden & $\begin{array}{l}18.98 \\
(3.84)\end{array}$ & $\begin{array}{l}18.04 \\
(4.10)\end{array}$ & $\begin{array}{c}21.94 \\
(3.75)\end{array}$ & $\begin{array}{l}11.51 \\
(6.70)\end{array}$ & $\begin{array}{l}11.08 \\
(7.22)\end{array}$ \\
\hline Average across countries & $\begin{array}{l}19.17 \\
(1.61)\end{array}$ & $\begin{array}{l}19.40 \\
(1.59)\end{array}$ & $\begin{array}{l}21.65 \\
(1.92)\end{array}$ & $\begin{array}{c}7.65 \\
(3.22)\end{array}$ & $\begin{array}{c}7.59 \\
(3.48)\end{array}$ \\
\hline $\begin{array}{l}\text { Student-level variables } \\
\text { Class-level variables } \\
\text { School-level variables } \\
\text { Only schools with }>1 \text { class } \\
\text { School fixed effects } \\
\text { Exclude tracked schools }\end{array}$ & $\nu$ & v & v & 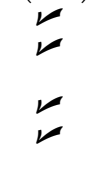 & $\nu$ \\
\hline \multicolumn{6}{|c|}{$\begin{array}{l}\text { NoTE.-Weighted least squares regressions using students' sampling probability as weight. Each } \\
\text { entry is the coefficient on the peers' index of books at home from a separate regression. Standard errors } \\
\text { (in parentheses) are robust to clustering at the school level. Student-level variables are student's sex } \\
\text { and age, parents' origin, language spoken at home, index of number of books at home, and number } \\
\text { of persons living in the household. Class-level variables are class size, class size squared, teacher's sex, } \\
\text { education, experience, and experience squared. School-level variables are community size, average daily } \\
\text { instruction hours, shortage of staff, teaching material, and buildings. Tracked schools are those for } \\
\text { which principals state that fourth-grade classes are formed on the basis of ability. }\end{array}$} \\
\hline
\end{tabular}

five categories. ${ }^{8}$ In each case, the peer variable for student $i$ used in the regressions is the leave-out mean for the classroom, omitting the value of the variable for student $i$ from the calculation of the mean.

We find a relatively consistent pattern of results for all six countries in our sample in table 5 . The size of the estimated peer effect is similar across the specifications with and without school- and class-level variables and is on the order of 15-22 for moving peer quality to the next higher category. Only in Norway does the peer coefficient fall when schoollevel covariates are added to the regression. Once we include school fixed effects in column 4, the effect always falls, although the amount of the change is different across countries. In Germany, the Netherlands, and Norway the peer effect weakens the most in these specifications, whereas there is little change in France. Excluding schools that form classes on the basis of student ability predictably changes the results only in France and the Netherlands, the two countries with moderate shares of students in schools that form classes on the basis of ability (see table 1). Curiously,

${ }^{8}$ We also experimented with assigning midpoints to the categories to form an alternative cardinal variable, with roughly similar results. 
estimated peer effects are larger when the schools that report tracking are excluded for the Netherlands.

One reason for the high variation in the coefficients from the fixedeffects models is that the standard errors of these estimates are reasonably large, so that the effects for each individual country cannot be estimated very precisely. If we believe that the peer effects are the same in each country, then it makes sense to combine the estimates into a single estimate. The average of the six coefficients in the fixed-effects specification in column 4, weighted by the inverse of the sampling variance, is 7.6. If the variation in country-level estimates around this overall mean is due only to sampling variation, then the standard error for the meta-estimate is 3.2. ${ }^{9}$ This estimate is much more precise than the country-level estimates, and it is significant at the $5 \%$ level. One concern is with the results for Sweden, because we found some evidence for nonrandom assignment and targeted classroom resources for Sweden above. The meta-estimate for the countries without Sweden is only slightly lower.

Our results show that standard OLS estimates of the peer effect may be biased upward substantially if the within-school results are indeed reliable estimates of the true peer effect. One reason why even the fixedeffects estimates may be biased is the presence of immigrant children. We showed above that immigrant children are often not randomly assigned to classes within schools, and the classes with many immigrant children may get different resources. Since immigrants in these countries tend to be of lower socioeconomic status (the index for books at home is on average 3.15 for immigrant families in the six countries but 3.56 for nonimmigrant families), part of the peer effect may be explained by the nonrandom allocation of immigrants.

In order to probe this, we reran the regressions in table 5 including the fraction of foreign-born children in the class and the fraction of children speaking a foreign language at home. This attenuates the estimated peer effects at most very slightly. ${ }^{10}$ We also experimented with regressions on the subsample of schools with few immigrant children. However, most sample countries have enough immigrants that there are relatively few such schools, leading to small samples and hence imprecise estimates. These results indicate that the effect of immigrant children in a class seems to be relatively well captured by our family background variable.

A further question is whether peer effects vary across students. This

${ }^{9}$ The sampling variance of the mean is obtained as $v=\left(\sum v_{c}^{-1}\right)^{-1}$, where $v_{c}$ is the sampling variance of the estimate for country $c$. One interpretation of this calculation is that the country average is the minimum distance estimate of the common peer effect across countries.

${ }^{10}$ Including measures from the school questionnaire on the share of economically disadvantaged students or the share of students leaving before the end of the academic year as alternative school-level variables did not change the results. 
Table 6

Regressions for Reading Test Score on Peer Composition and Interactions with Individual Family Background

\begin{tabular}{|c|c|c|c|c|c|c|}
\hline \multirow[b]{2}{*}{ Country } & \multicolumn{2}{|r|}{ (1) } & \multicolumn{2}{|r|}{ (2) } & \multicolumn{2}{|c|}{ (3) } \\
\hline & $\begin{array}{l}\text { Peer } \\
\text { Effect }\end{array}$ & Interaction & $\begin{array}{l}\text { Peer } \\
\text { Effect }\end{array}$ & Interaction & $\begin{array}{c}\text { Peer } \\
\text { Effect }\end{array}$ & Interaction \\
\hline Germany & $\begin{array}{l}17.58 \\
(3.03)\end{array}$ & $\begin{array}{c}.82 \\
(1.04)\end{array}$ & $\begin{array}{c}5.92 \\
(6.21)\end{array}$ & $\begin{array}{c}.55 \\
(1.08)\end{array}$ & $\begin{array}{c}7.09 \\
(6.37)\end{array}$ & $\begin{array}{c}.34 \\
(1.11)\end{array}$ \\
\hline France & $\begin{array}{c}20.94 \\
(3.12)\end{array}$ & $\begin{array}{c}2.46 \\
(1.43)\end{array}$ & $\begin{array}{l}21.37 \\
(9.01)\end{array}$ & $\begin{array}{c}1.36 \\
(1.68)\end{array}$ & $\begin{array}{c}16.01 \\
(11.98)\end{array}$ & $\begin{array}{c}3.02 \\
(2.24)\end{array}$ \\
\hline Iceland & $\begin{array}{l}17.32 \\
(5.82)\end{array}$ & $\begin{array}{l}1.43 \\
(1.66)\end{array}$ & $\begin{array}{c}11.67 \\
(11.31)\end{array}$ & $\begin{array}{c}.76 \\
(1.87)\end{array}$ & $\begin{array}{c}8.66 \\
(11.41)\end{array}$ & $\begin{array}{c}.24 \\
(1.83)\end{array}$ \\
\hline Netherlands & $\begin{array}{l}17.74 \\
(4.49)\end{array}$ & $\begin{array}{l}-.34 \\
(1.36)\end{array}$ & $\begin{array}{l}-.50 \\
(8.90)\end{array}$ & $\begin{array}{l}2.53 \\
(1.53)\end{array}$ & $\begin{array}{c}8.23 \\
(9.79)\end{array}$ & $\begin{array}{c}3.21 \\
(1.34)\end{array}$ \\
\hline Norway & $\begin{array}{l}15.35 \\
(7.58)\end{array}$ & $\begin{array}{c}.16 \\
(1.76)\end{array}$ & $\begin{array}{c}-3.71 \\
(8.13)\end{array}$ & $\begin{array}{c}.94 \\
(1.69)\end{array}$ & $\begin{array}{c}-3.43 \\
(8.26)\end{array}$ & $\begin{array}{c}1.18 \\
(1.76)\end{array}$ \\
\hline Sweden & $\begin{array}{l}19.91 \\
(3.94)\end{array}$ & $\begin{array}{l}-1.35 \\
(1.14)\end{array}$ & $\begin{array}{l}11.85 \\
(6.99)\end{array}$ & $\begin{array}{l}-.41 \\
(1.19)\end{array}$ & $\begin{array}{l}11.59 \\
(7.22)\end{array}$ & $\begin{array}{l}-.60 \\
(1.22)\end{array}$ \\
\hline $\begin{array}{l}\text { Average across } \\
\text { countries }\end{array}$ & $\begin{array}{c}18.81 \\
(1.64)\end{array}$ & $\begin{array}{l}.38 \\
(.54)\end{array}$ & $\begin{array}{c}7.30 \\
(3.26)\end{array}$ & $\begin{array}{c}.77 \\
(.58)\end{array}$ & $\begin{array}{c}7.31 \\
(3.46)\end{array}$ & $\begin{array}{l}.95 \\
(.59)\end{array}$ \\
\hline $\begin{array}{l}\text { Student-level } \\
\text { variables }\end{array}$ & 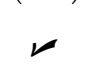 & $\nu$ & $\nu$ & $\nu$ & $\nu$ & $\nu$ \\
\hline $\begin{array}{l}\text { Only schools with }> \\
1 \text { class } \\
\text { School fixed effects } \\
\text { Exclude tracked } \\
\text { schools }\end{array}$ & & & $\nu$ & $\nu$ & 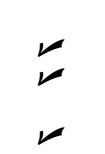 & $\mathscr{v}$ \\
\hline $\begin{array}{l}\text { Note. - Weighted leas } \\
\text { on the peers' index of b } \\
\text { individual-level dummy } \\
\text { of columns. Standard erro } \\
\text { sex and age, parents' or } \\
\text { number of persons livin } \\
\text { fourth-grade classes are }\end{array}$ & $\begin{array}{l}\text { luares } \mathrm{r} \\
\mathrm{ks} \text { at h} \\
\text { iable fo } \\
\text { are robu } \\
\mathrm{h} \text {, langu } \\
\mathrm{n} \text { the } \mathrm{h} \\
\text { med on }\end{array}$ & $\begin{array}{l}\text { ressions using } \\
\text { ne (peer effect } \\
>100 \text { books a } \\
\text { to clustering } \\
\text { e spoken at } \\
\text { isehold. Track } \\
\text { te basis of abi }\end{array}$ & $\begin{array}{l}\text { tudents' sa } \\
\text { columns) } \\
\text { home (int } \\
\text { the schoo } \\
\text { me, index } \\
\text { d schools } \\
\text { ty. }\end{array}$ & $\begin{array}{l}\text { apling probab } \\
\text { nd interactior } \\
\text { raction colum } \\
\text { level. Student- } \\
\text { of the numb } \\
\text { re those for }\end{array}$ & $\begin{array}{l}\text { y as weigl } \\
\text { rm of pe } \\
\text { are shov } \\
\text { el variabl } \\
\text { of books } \\
\text { ich princ }\end{array}$ & $\begin{array}{l}\text { t. Coefficients } \\
\text { ers' index and } \\
n \text { in each pair } \\
\text { s are student's } \\
\text { at home, and } \\
\text { pals state that }\end{array}$ \\
\hline
\end{tabular}

could give insights into the optimal assignment of students to classes. When students from a lower social background profit more from their peers' background than students from a high social background, more heterogeneous classes would benefit overall performance (Glewwe 1997). To investigate this, we add interaction effects between the peer variable and the individual variable books at home to the regressions presented in table 5. Since about half the students have more than 100 books at home, we interact the peer average with a dummy indicating whether the individual reports more than 100 books at home. The results are presented in table 6. Peer effects seem to be stronger for students with a higher social background in France and the Netherlands, and they are stronger for students with a lower social background in Sweden. The meta-estimate of the interaction is small and insignificant. 


\section{Measurement Error and Missing Students}

Survey reports are subject to a lot of measurement error. In our case, measurement error in the books at home variable implies that there is measurement error in both the individual- and the peer-level regressors. In addition, the peer measure is not based on all students in a class because some students have not been sampled and others have not responded to the respective question. This problem will also arise in many studies based on administrative data, which frequently use lagged test scores as a peer measure, since test taking may be incomplete or lagged scores cannot be matched to all students. Both these measurement problems will interact in leading to biased estimates of the peer effect in a nonstandard way.

In order to investigate the impact of measurement error in our setup, we will return to the model we outlined in equations (1)-(3) above. In order to focus on the variables of interest, consider a simplified version of equation (1) with only the individual-level and the peer group regressors but no other covariates:

$$
y_{i c s}=\beta X_{i c s}+\lambda \bar{X}_{(-i) c s}+\epsilon_{i c s} .
$$

Moreover, to focus on the role of measurement error, we set $\mu_{c s}=0$; that is, the error term has no class- or school-level component. Hence we abstract from the biases arising from correlated effects. In practice, these might of course exist on top of any biases from measurement error.

The student background variable $X_{i c s}$ is still given by equation (2), but this variable is not directly observed. Instead we observe

$$
\tilde{X}_{i c s}=X_{i c s}+u_{i c s}=\eta_{c s}+v_{i c s}+u_{i c s}
$$

where $u_{i c s}$ is a classical measurement error. Moreover, the observed peer variable is computed only from the subset of observed peers, whereas students are actually affected by all peers in (6).

We do not assume that students are missing at random. Instead our derivations assume that the $v_{i c s}$ for missing students are drawn from a distribution that may differ from the distribution for the observed students, but this distribution is independent of classroom assignment or of $\epsilon_{i c s}$. This allows for the possibility, for example, that the probability of a student being missing depends on his or her background characteristics. ${ }^{11}$

Our argument above has been that the common component of student background, $\eta_{c s}$, arises only at the school level. Hence, we can think of our standard OLS results corresponding to those with $\sigma_{\eta}^{2}>0$ and the

${ }^{11}$ Sojourner's (2008) work and discussions with the author first alerted us to the possibility that assumptions weaker than missing at random are feasible when students are (quasi) randomly assigned to classrooms. 
within-school results to $\sigma_{\eta}^{2}=0$ because this component has been absorbed by the fixed effects.

In this setup, the OLS estimate of $\lambda$ will converge to

$$
\begin{aligned}
\operatorname{plim} \hat{\lambda}_{\text {OLS }}= & \beta \frac{(\bar{n}-1) \sigma_{u}^{2} \sigma_{\eta}^{2}}{\left(\sigma_{v}^{2}+\sigma_{u}^{2}\right)\left(\bar{n} \sigma_{\eta}^{2}+\sigma_{v}^{2}+\sigma_{u}^{2}\right)} \\
& +\lambda \frac{[(\bar{n}-1) /(\bar{N}-1)] \sigma_{v}^{2}\left(\sigma_{\eta}^{2}+\sigma_{v}^{2}+\sigma_{u}^{2}\right)+(\bar{n}-1) \sigma_{\eta}^{2}\left(\sigma_{v}^{2}+\sigma_{u}^{2}\right)}{\left(\sigma_{v}^{2}+\sigma_{u}^{2}\right)\left(\bar{n} \sigma_{\eta}^{2}+\sigma_{v}^{2}+\sigma_{u}^{2}\right)},
\end{aligned}
$$

as we show in the appendix. The term $\bar{N}$ is the average number of students in a classroom, $\bar{n}$ is the average number of students sampled in each class, and all the variances refer to the distributions of the relevant variables in the subpopulation of observed students.

In order to understand the different sources of measurement error and the sign of the bias, it is instructive to look at some special cases. First, consider the case in which all students in each class are sampled, so the only problem is classical measurement error. In this case,

$$
\begin{aligned}
\operatorname{plim} \hat{\lambda}_{\text {OLS }}= & \beta \frac{(\bar{N}-1) \sigma_{u}^{2} \sigma_{\eta}^{2}}{\left(\sigma_{v}^{2}+\sigma_{u}^{2}\right)\left(\bar{N} \sigma_{\eta}^{2}+\sigma_{v}^{2}+\sigma_{u}^{2}\right)} \\
& +\lambda \frac{\sigma_{v}^{2}\left(\bar{N} \sigma_{\eta}^{2}+\sigma_{v}^{2}+\sigma_{u}^{2}\right)+(\bar{N}-1) \sigma_{\eta}^{2} \sigma_{u}^{2}}{\sigma_{v}^{2}\left(\bar{N} \sigma_{\eta}^{2}+\sigma_{v}^{2}+\sigma_{u}^{2}\right)+\sigma_{u}^{2}\left(\bar{N} \sigma_{\eta}^{2}+\sigma_{v}^{2}+\sigma_{u}^{2}\right)} .
\end{aligned}
$$

It is easy to see in this formulation that the second term implies an attenuation bias of $\lambda$ if there is classical measurement error in $X_{i c s}$. This measurement error will carry over to $\bar{X}_{(-i) c s}$ and lead to the standard attenuation. Since $\lambda$ is likely positive, this will imply an underestimate of $\lambda$. From equation (8), it becomes clear that the attenuation is greater when some students in the class are not sampled. If $\sigma_{\eta}^{2}>0$, a second component of the bias arises, and this is captured by the first term in equation (8) or (9). The individual-level regressor $X_{i c s}$ is also subject to error, which will lead to an attenuation of the estimated $\hat{\beta}$. Since the peer variable $\bar{X}_{(-i) c s}$ contains information on $\eta_{c s}$, part of the signal in the individual-level regressor will load onto the peer coefficient. This term is positive and hence yields an upward bias.

Because of these two conflicting sources of bias, it is impossible to tell what the net effect of the bias on $\hat{\lambda}_{\text {OLS }}$ is. The first term can dominate when $\beta$ is sufficiently large compared to $\lambda$. Hence measurement error may not lead to an underestimate of the peer effect in the standard OLS specification. 
The within-school model corresponds to the case in which $\sigma_{\eta}^{2}=0$, the first term in equations (8) and (9) vanishes, and we have

$$
\operatorname{plim} \hat{\lambda}_{W}=\lambda\left(\frac{\bar{n}-1}{\bar{N}-1}\right) \frac{\sigma_{v}^{2}}{\sigma_{v}^{2}+\sigma_{u}^{2}},
$$

so that the peer effect is now underestimated. Hence, measurement error alone may explain why we find lower peer effects in the fixed-effects estimates in table 5 .

Furthermore, consider the within estimator of the individual-level covariate

$$
\operatorname{plim} \hat{\beta}_{W}=\beta \frac{\sigma_{v}^{2}}{\sigma_{v}^{2}+\sigma_{u}^{2}} .
$$

The bias in this coefficient is just the standard classical attenuation bias. Moreover, the attenuation bias terms, $\sigma_{v}^{2} /\left(\sigma_{v}^{2}+\sigma_{u}^{2}\right)$, are the same in the expressions for plim $\hat{\beta}_{W}$ and plim $\hat{\lambda}_{W}$. Since $\bar{N}$ and $\bar{n}$ are observable in our data, this yields

$$
\operatorname{plim} \frac{\hat{\lambda}_{W}}{\hat{\beta}_{W}}\left(\frac{\bar{N}-1}{\bar{n}-1}\right)=\frac{\lambda}{\beta},
$$

which suggests that the ratio of the coefficient on the peer variable and the individual-level background variable can be estimated consistently. It tends to be difficult to interpret the magnitudes of the peer effect estimate in any case. One way to facilitate this interpretation is to look at this ratio.

The more standard way to address the measurement error problem is to rely on instruments for both $X_{i c s}$ and $\bar{X}_{(-i) c s}$. Recall that in our case the background variable $X_{i c s}$ is the parents' report of the number of books at home. The same question was asked of the students as well, so we use the students' report of the number of books at home as our instrument for the parents' report and the peer mean of the students' report as an instrument for the peer variable. Of course, the errors in parents' and students' reports may well be correlated. Nevertheless, using independent reports by different individuals on the same variable and assuming independent errors are a standard strategy in the literature when such measures are available (see, e.g., Ashenfelter and Krueger 1994). We therefore pursue this avenue here as well.

In the classical measurement error case with an unbounded support for $X_{i c s}$, the IV estimate of $\lambda$ will converge to

$$
\operatorname{plim} \hat{\lambda}_{\mathrm{IV}}=\lambda\left(\frac{\bar{n}-1}{\bar{N}-1}\right) \frac{\bar{N} \sigma_{\eta}^{2}+\sigma_{v}^{2}}{\bar{n} \sigma_{\eta}^{2}+\sigma_{v}^{2}} .
$$


This turns out to be the same as the expression in equation (8) with $\sigma_{u}^{2}=0$, so IV solves the standard measurement error problem. It does not resolve the attenuation in the peer effect that arises because we do not sample all the students in a class. For the within estimator, equation (12) becomes

$$
\operatorname{plim} \hat{\lambda}_{\mathrm{IV}, \mathrm{W}}=\lambda\left(\frac{\bar{n}-1}{\bar{N}-1}\right)
$$

This again suggests that the within-school IV estimate is simple to adjust for the sampling bias using the actual means $\bar{N}$ and $\bar{n}$ in our data. Our adjusted IV estimator will therefore be

$$
\hat{\lambda}_{\text {IVadj }}=\hat{\lambda}_{\text {IV }}\left(\frac{\bar{N}-1}{\bar{n}-1}\right) \text {. }
$$

The first stages corresponding to our IV regressions indicate that the relevant instruments both for the individual-level regressor and for the peer variable are always highly significant. The $t$-statistics on the students' report of books at home are above 7 and typically above 10, and the corresponding $F$-statistics are also large. ${ }^{12}$ This indicates that our IV models are not likely to suffer from any small-sample bias.

One important caveat to these derivations is of course that our background and peer variable, books at home, is categorical and hence has bounded support. In this case, measurement error will by necessity be nonclassical. Moreover, Kane, Rouse, and Staiger (1999) point out that the IV estimator is biased upward when the mismeasured regressor is binary. The same will be true if the regressor is multivalued but bounded. For our application this implies that the IV estimates may actually be biased upward. In this case, once we control for school fixed effects, OLS and IV would bracket the true result. However, as we discussed above, mistakes in parents' and children's reports of books at home may be correlated. This would bias the IV estimates toward OLS, and the true peer effect could therefore be larger than the IV result.

Before we turn to our results, it is important to point out that Sojourner (2008), in an independent and complementary analysis, also considers the estimation of peer effects with missing students. ${ }^{13}$ His setup allows for more general processes that generate missing students. In particular, Sojourner's results are valid under our assumptions and random assignment

\footnotetext{
${ }^{12}$ The only exception is the Netherlands, where the instrument for the peer variable has a $t$-statistic of 3.15 .

${ }^{13}$ This problem has also been recognized by Altonji (1988), although his approach does not solve it completely.
} 
Table 7

OLS and IV Regressions for Reading Test Score on Books at Home and Peer Composition

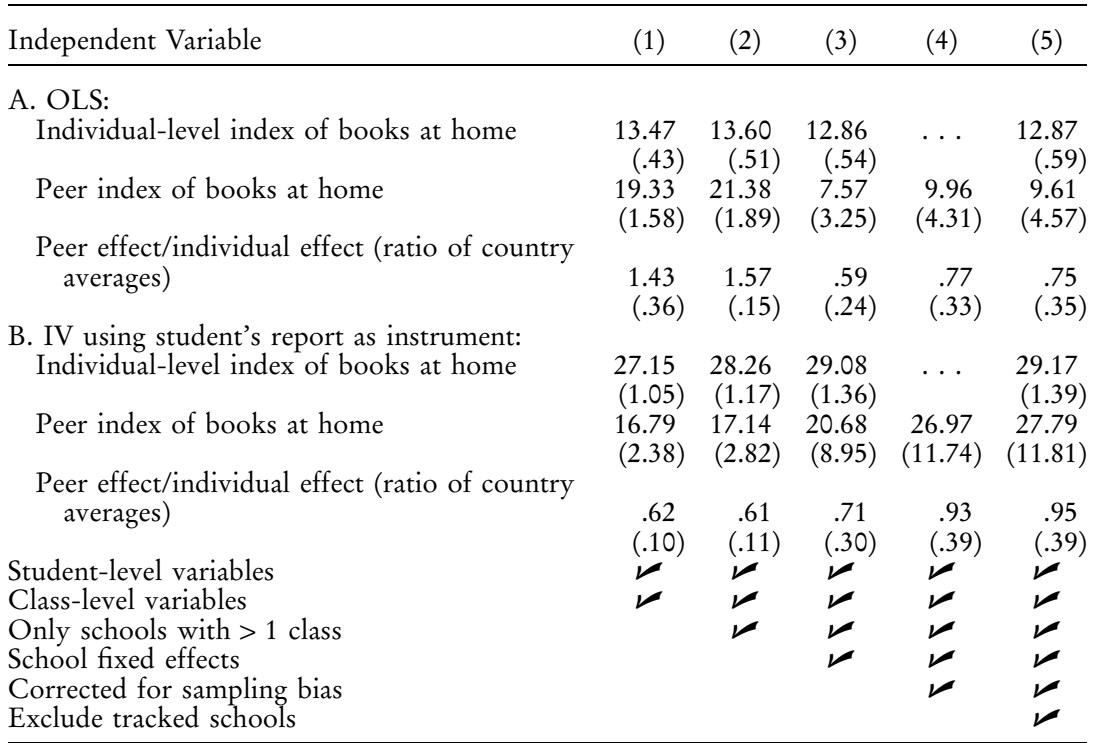

Note.-Weighted least squares and instrumental variable regressions using students' sampling probability as weight. Averages across six countries are shown. Standard errors are robust to clustering at the school level. In panel B the individual's and peers' index of the number of books at home from the home questionnaire are instrumented by the individual's and peers' index of books at home from the student questionnaire. A dummy for missing observations for the books variable from the student questionnaire has been added to not further restrict the sample size. Student-level variables are student's sex and age, parents' origin, language spoken at home, index of number of books at home, and number of persons living in the household. Class-level variables are class size, class size squared, teacher's sex, education, experience, and experience squared. The correction factor for sampling bias in cols. 4 and 5 is $(N-$ $1) /(n-1)$. Tracked schools are those for which principals state that fourth-grade classes are formed on the basis of ability.

of students to classrooms but not vice versa. He suggests an alternative peer effects estimator for his conditions. However, we explicitly consider measurement error in the background variable. This is not part of Sojourner's analysis. ${ }^{14}$

Table 7 presents the results from OLS regressions similar to the earlier ones in panel A and IV results in panel B. Both the individual and peers' indices of the number of books at home from the home questionnaire are instrumented by the individual and peers' indices of books at home

${ }^{14}$ We suspect that our procedure of applying the standard peer effects estimator to the sample of observed students and correcting the estimates as ex post for missing students as in (11) or (14) should be more efficient than the Sojourner (2008) $p$-weight estimator under the conditions in which our analysis is valid. The reason is that the $p$-weight estimator involves a large number of additional covariates that will not affect the residual variance under our scenario. However, we do not have a formal proof for this conjecture. 
from the student questionnaire. We also present estimates for the ratio of the peer effect and the individual effect. The table displays only averages over all our six countries. ${ }^{15}$

Instrumenting the individual-level index of books at home more than doubles the coefficient in all specifications. This may suggest a large amount of measurement error in the books at home variable. It could also imply that the IV estimate is biased upward because the regressor and instrument have bounded support.

More interestingly, the coefficient on the peer variable does not increase in the IV specifications when only student- and class-level variables are included (cols. 1 and 2), and, in fact, it falls slightly. This is consistent with our discussion of equations (8), (9), and (12) above. Measurement error in the peer regressor may actually lead to an upward bias in the OLS specifications if $\sigma_{\eta}^{2}>0$, as can be seen in equation (8). Moreover, the ratio of the coefficient on the peer effect and the individual effect is around 1.5. This is much too large to be believable and further underscores that these estimates are likely subject to bias from measurement error (and/ or correlated effects). ${ }^{16}$

Things are very different when we go to the within-school specification in column 3. The coefficient on the individual-level regressor changes little compared to that in column 2, whereas the coefficient on the peer variable falls to a third in the OLS specification. This is consistent with the comparison of equations (8) and (10). The within specification removes the first (positive) bias term in (8), and it exacerbates the standard attenuation bias by removing the potentially important variance component $\sigma_{\eta}^{2}$. In the IV results, however, the coefficient on the peer variable is fairly similar to that in column 2. A comparison of equations (12) and (13) suggests that the IV coefficient should fall going to the within estimate. However, our result could easily be due to sampling variation. Overall, we conclude that the relative stability of the IV estimates across columns

\footnotetext{
${ }^{15}$ The averages for the peer and individual effects are obtained as before. The ratio is estimated as the ratio of the country averages (rather than the average of the ratios for each country). This is the efficient estimate under the assumption that the underlying coefficients are the same in each country, and we want to recover this common coefficient. The estimate of the ratio will also generally be biased in small samples (because of the sampling error and Jensen's inequality). This bias will be minimized by taking averages first and then forming the ratio.

${ }^{16}$ It may seem curious that the standard error for the ratio of the peer and individual effects is smaller for the IV estimates in cols. 1 and 2 than for the corresponding OLS estimates (although the standard errors on the coefficients for the individual and peer books variables go up in the IV estimation compared to OLS). This results from the fact that the coefficient for the individual-level effect goes up in the IV results, and this coefficient enters the denominator of the standard error calculation.
} 
is more consistent with an explanation based on measurement error than one based on correlated effects.

The ratio of the peer effect to the individual effect is now in the range of 0.6-0.7. This is more sensible since we expect the peer effect to be smaller than the individual effect, although it still reflects a large estimate of the peer effect. Moreover, the OLS and IV estimates of the ratio in column 3 are now fairly similar. This is what we expect from equations (11) and (13). The IV estimate is slightly higher than the OLS one. This is consistent with the idea that our IV estimates are biased upward because the regressor and instrument have bounded support. This reasoning would suggest that the OLS estimate of the ratio might be the more reliable one than the IV estimate. Of course, the estimates in column 3 are still biased because not all students are sampled.

We therefore implement the correction for the sampling bias as suggested in equations (11) and (14) in column $4 .{ }^{17}$ This affects both the peer effects estimate and the estimate of the ratio. The estimates are about $30 \%$ higher, indicating potentially substantial peer effects. As before, excluding tracked schools in column 5 makes little difference to the results. Our best estimate for the ratio of the peer and individual effects is therefore around 0.75 , which is substantial.

We have tried to argue that the allocation of students into classrooms within schools is approximately random. Nevertheless, it is not possible to rule out some sorting of students in practice. Could our results have been generated simply by sorting of students while true peer effects are zero? It is impossible to rule out this possibility completely. This results from the fact that a general enough model of student achievement has enough free parameters to generate both the test results for random assignment in table 4 and the regression results in tables 5-7. In particular, a very small classroom-level variance component $\sigma_{\eta}^{2}$ (relative to the individual-level component $\sigma_{v}^{2}$ ), which is highly correlated with the classroom-level shock $\sigma_{\mu}^{2}$, combined with a commensurate individual-level effect on the background variable $X_{i c s}$, can generate all of our result. Since this combination of parameter values occupies a small region close to (but not on) the boundary of the feasible parameter space, it strikes us as rather unlikely. ${ }^{18}$

\section{Effect Sizes}

Of course, even if we identify a positive peer effect, one might ask whether we care much about the precise magnitude of the coefficient on

\footnotetext{
${ }^{17}$ The adjustment for sampling bias is applied to the individual country estimates of the peer effects before taking country averages.

${ }^{18}$ Detailed derivations of these claims and power calculations from a simulation study are available from the authors on request.
} 
Table 8

Effect Sizes

\begin{tabular}{lcccccc}
\hline & $\begin{array}{c}\text { SD Test } \\
\text { Score } \sigma_{y} \\
(1)\end{array}$ & $\begin{array}{c}\text { SD Peer } \\
\text { Variable } \\
\sigma_{\bar{X}} \\
(2)\end{array}$ & $\begin{array}{c}\text { SD Peer } \\
\text { Variable } \\
\text { Adjusted } \sigma_{\bar{X}} \\
(3)\end{array}$ & $\begin{array}{c}\text { Peer } \\
\text { Effect } \hat{\lambda} \\
(4)\end{array}$ & $\begin{array}{c}\text { Effect Size } \\
\sigma_{\bar{X}} \hat{\lambda} / \sigma_{y} \\
(5)\end{array}$ & $\begin{array}{c}\text { Peer Effect/ } \\
\text { Individual } \\
\text { Effect } \\
(6)\end{array}$ \\
\hline Germany & 60.00 & .459 & .362 & 23.90 & .144 & .52 \\
France & 65.45 & .646 & .539 & 60.62 & .499 & 2.11 \\
Iceland & 67.58 & .348 & .251 & -2.17 & -.008 & 1.47 \\
Netherlands & 56.46 & .678 & .532 & -25.00 & -.236 & .15 \\
Norway & 77.12 & .372 & .301 & 3.05 & .012 & -.24 \\
$\begin{array}{l}\text { Sweden } \\
\text { Average across }\end{array}$ & 61.50 & .461 & .400 & 30.83 & .201 & 1.34 \\
$\quad$ countries & 64.68 & .494 & .397 & 26.97 & .166 & .77 \\
\hline
\end{tabular}

Note.-Column 3 is the square root of the covariance between the peer variables index of books at home taken from the student and the home questionnaire. The estimates of the peer effects in col. 4 are taken from col. 4 in table 7 . The results in col. 5 are calculated as col. $4 \times$ col. $3 / \mathrm{col}$. 1 . The results in col. 6 are calculated as the ratio of the peer coefficient to the individual coefficient from the OLS regressions in col. 4 in table 7.

the peer variable. Books at home is at best a fairly imperfect proxy for the family background of peers. Hence, we may care more about statistical significance than the actual magnitudes. But this strikes us as an overly pessimistic view. We will therefore proceed to use three different methods to assess the economic magnitude of the effects.

It is common in the literature to report effect sizes of the peer effects estimates, so this helps to facilitate comparisons with other studies using different peer measures. Effect sizes are typically calculated as $\sigma_{\bar{X}} \hat{\lambda} / \sigma_{y}$, where $\sigma_{\bar{X}}$ is the within-country variation in the peer variable and $\sigma_{y}$ is the within-country variation in the test scores. This quantifies the peer effect as the impact of a one-standard-deviation change in peer background in terms of individual-level standard deviations of the outcome variable.

One complication with this measure in our context is that the standard deviation of the peer variable is not an unbiased measure of $\sigma_{\bar{X}}$ because of the measurement error. However, since we have both the parents' and the children's reports for books at home, the covariance of the two is a measure of the variance of the true variable if both reports are subject only to uncorrelated classical measurement errors. Both our estimate of $\sigma_{\bar{X}}$ and the IV estimate of $\hat{\lambda}$ therefore rely on the classical measurement error model being a good approximation in our case and the parents' and children's reports being uncorrelated.

We report the effect size measure and the necessary ingredients in table 8. As before, the effect sizes vary quite widely across countries. The variation in effect sizes comes almost exclusively from variation in the peer coefficients. The average effect size across countries is 0.17 . This is larger than most of the estimates in the literature. The bulk of the reported effect sizes are in the range of $0.05-0.10$. Our estimate is at the upper end 
of that range but well below the highest estimates reported in studies by Hoxby (2000), Boozer and Cacciola (2001), and McEwan (2003).

Another way to gauge the size of our estimates is to compare them to the effect of a well-known alternative intervention. For this comparison we picked the change in class size in the Tennessee STAR experiment, as reported by Krueger (1999). Krueger reports a class size effect of -0.81 per student in third grade (his table 7 ), which is closest to the age group in our study. This corresponds to an effect size for a change in class size by one student of about 0.03 . A one-standarddeviation change in peer composition therefore corresponds to a change in class size by about five students. This suggests to us that our estimate is fairly large in comparison.

Of course, the size of the peer effect estimate also depends on how well our family background measure actually captures the relevant characteristics of students. It is therefore useful to compare the peer coefficient to the individual-level coefficient as we have done already in table 7 . If books at home are a good predictor of reading success, then the coefficient on own books at home will be larger and the peer coefficient will also be larger, and vice versa. Column 6 in table 8 reports the ratio of the two. The average based on the OLS results is 0.77 , indicating that the estimate of the peer effect is large compared to the estimate of the individual-level effect, since we would expect peers' background to matter much less than own background. One drawback of this comparison is that it depends on what other variables are controlled for in the regression. For example, some studies in the literature control for multiple family background characteristics at the individual level. This makes a comparison across studies very difficult.

One reason why our estimates seem relatively large might be that we are careful about the measurement error in the peer effects variable. However, adjusting for measurement error lowers the estimate of $\sigma_{\bar{X}}$ and raises the estimate of $\hat{\lambda}$, so this cuts two ways. However, the upward adjustment in $\hat{\lambda}$ is much more important. Calculating the effect size on the basis of the estimates ignoring measurement error yields a value of only 0.06 , about a third of the size of our IV results. Hence, the treatment of measurement error may be rather important, particularly in studies based on survey data, such as Schindler Rangvid (2007) and Schneeweis and WinterEbmer (2007). A further explanation for the large effect sizes could be that we estimate the cumulative impact of peers if classroom composition is fixed over the previous 4 years and not the incremental effect of a valueadded specification. We should also point out that our confidence intervals are fairly large because the within-school and IV estimates are relatively noisy. 


\section{Conclusion}

Peer effects are potentially a major input into the process of educational production but are difficult to estimate empirically. We estimate peer effects across classes within primary schools and argue that classes within schools are formed randomly with respect to family background. We find that a one-standard-deviation change in our student background measure of peer composition leads to a 0.17 -standard-deviation change in reading test scores of fourth graders across our sample of six European countries. This is slightly larger than most previous estimates in the literature. The individual country estimates are relatively noisy so that we feel that most is learned from the country averages. For Sweden, the estimated effects are not different from the average for the other countries, although we found some evidence that students may not be randomly allocated to classes in Sweden.

We have argued that there is little evidence for systematic sorting into classrooms within schools for the other countries and for different classes receiving different observable instructional resources. Hence, comparing students in different classes within schools should be an effective way of dealing with any selection at the school level. Surprisingly, we find that this selection does not seem to be very important once we take measurement error issues into account. We have argued that the within-school estimator solves the measurement error problem when we look at the ratio of the peer effect and the individual effect. The OLS and withinschool results alone are consistent with an explanation based either on selection of students into schools and correlated effects at the school level or on measurement error because the estimated peer effects drop substantially when we go from the across-school to the within-school results.

As an alternative to the OLS results we also present IV estimates. Unlike the OLS estimator, the IV estimator solves the measurement error problem in the case of both the across-school and the within-school regressions. The IV results are very similar regardless of whether we introduce school fixed effects. This is consistent with a measurement error explanation but not with a role for correlated effects at the school level. The discussion in this literature seems dominated with solving the selection issues, whereas little attention is being paid to the measurement error and sampling issues, which we find to be important in our data.

\section{Appendix}

We are interested in estimating equation (6) in the text,

$$
y_{i c s}=\beta X_{i c s}+\lambda w_{c s}+\epsilon_{i c s}
$$


where $w_{c s}=\bar{X}_{(-i) c s}$ is the peer effect. The background variable $X_{i c s}$ is given by

$$
\begin{aligned}
X_{i c s} & =\eta_{c s}+v_{i c s}, \\
E\left(v_{i c s}\right) & =0,
\end{aligned}
$$

and $v_{i c s}$ is independent and identically distributed (iid) across observations. Measurement error is classical so that the measured variable is

$$
\begin{aligned}
\tilde{X}_{i c s} & =X_{i c s}+u_{i c s}, \\
E\left(u_{i c s}\right) & =0,
\end{aligned}
$$

with $u_{i c s}$ also iid across observations. Finally, we assume $E\left(X_{i c s} \epsilon_{j c s}\right)=$ $E\left(w_{c s} \epsilon_{i c s}\right)=0$ for all $i, j$.

The OLS estimator $\hat{\beta}_{\mathrm{OLS}}$ is

$$
\begin{gathered}
\hat{\beta}_{\mathrm{OLS}}= \\
\frac{\sum(\tilde{w}-\overline{\tilde{\tilde{w}}})^{2} \sum(y-\bar{y})(\tilde{X}-\overline{\tilde{X}})-\sum(\tilde{\tilde{w}}-\tilde{\tilde{w}})(\tilde{X}-\overline{\tilde{X}}) \sum(y-\bar{y})(\tilde{w}-\tilde{\tilde{w}})}{\sum(\tilde{X}-\tilde{\tilde{X}})^{2} \sum(\tilde{w}-\overline{\tilde{w}})^{2}-\left[\sum(\tilde{w}-\overline{\tilde{w}})(\tilde{X}-\overline{\tilde{X}})\right]^{2}},
\end{gathered}
$$

and an analogous expression holds for $\hat{\lambda}_{\text {OLs }}$. In order to derive the plims of the estimators, we will need the plims of the sums of squares and crossproducts in this expression. There are $N_{c s}$ students in a class. Even though $E\left(v_{i c}\right)=0$, because $N_{c s}$ is relatively small, $\bar{v}_{(-i) c s}$ will generally be different from zero. It is useful to distinguish $\bar{v}_{(-i) c s}$ from $\eta_{c s}$ because $\eta_{c s}$ will carry information about $X_{i c s}$ but $\bar{v}_{(-i) c s}$ will not.

Not all students are observed. Hence the plims of the variance terms are

$$
\begin{aligned}
& \operatorname{plim} \frac{1}{n} \sum_{i}\left(X_{i c s}-\bar{X}\right)^{2}=\sigma_{\eta}^{2}+\sigma_{v}^{2}, \\
& \operatorname{plim} \frac{1}{n} \sum_{i}\left(w_{c s}-\bar{w}\right)^{2}=\sigma_{\eta}^{2}+\frac{\sigma_{v}^{2}}{\bar{N}-1},
\end{aligned}
$$

where the sum is over observed students, $n$ is the total number of students in the sample, and $\bar{N}$ is average class size. Note that while the sum in the plims above is over sampled students, $w_{c s}$ is the peer mean among all students, that is,

$$
w_{c s}=\bar{X}_{(-i) c s}=\frac{1}{N_{c s}} \sum_{j=1, j \neq i}^{N_{c s}} X_{j c s}
$$

In order to interpret the plims, it is necessary to consider the process 
that generates missing students. If students are missing at random, the distribution of $v_{i c s}$ among observed and missing students will be the same. As a result, $\sigma_{v}^{2}$ in the expressions above is the population variance of $v_{i c s}$. However, our derivation holds for weaker conditions than missing at random. Instead suppose that the distribution of $v_{i c s}$ among missing students is different from that among observed students. Our derivations hold as long as these distributions are independent of classroom assignment. In the case in which the distribution of missing students is different, the interpretation of $\sigma_{v}^{2}$ in the expressions above is that of the variance of $v_{i c s}$ in the subpopulation of observed students. The key to our results is that all the plims of all the variance and covariance terms below will involve terms $\sigma_{v}^{2}$ only for this particular subpopulation. This comes from the fact that all the relevant variance and covariance terms will always involve at least one argument pertaining to observed students. As a result, all the variances in the plims always refer to the observed subpopulation.

We have a sample on $n_{c s} \leq N_{c s}$ students in the class. The peer mean in the sample is computed over observed students only. Hence the plims in terms of the observed variables $\tilde{X}_{i c s}$ and $\tilde{w}_{c s}=\overline{\tilde{X}}_{(-i) c s}$ in the sample are

$$
\begin{aligned}
& \operatorname{plim} \frac{1}{n} \sum_{i}\left(\tilde{X}_{i c s}-\overline{\tilde{X}}\right)^{2}=\sigma_{\eta}^{2}+\sigma_{v}^{2}+\sigma_{u}^{2}, \\
& \operatorname{plim} \frac{1}{n} \sum_{i}\left(\tilde{w}_{c s}-\overline{\tilde{w}}\right)^{2}=\sigma_{\eta}^{2}+\frac{\sigma_{v}^{2}}{\bar{n}-1}+\frac{\sigma_{u}^{2}}{\bar{n}-1} .
\end{aligned}
$$

We will also need various covariance terms below. These are

$$
\begin{aligned}
\operatorname{plim} \frac{1}{n} \sum_{i}\left(\tilde{X}_{i c s}-\overline{\tilde{X}}\right)\left(\tilde{w}_{c s}-\overline{\tilde{w}}\right) & =\sigma_{\eta}^{2}, \\
\operatorname{plim} \frac{1}{n} \sum_{i}\left(\tilde{X}_{i c s}-\overline{\tilde{X}}\right)\left(w_{c s}-\bar{w}\right) & =\sigma_{\eta}^{2}, \\
\operatorname{plim} \frac{1}{n} \sum_{i}\left(X_{i c s}-\bar{X}\right)\left(\tilde{w}_{c s}-\overline{\tilde{w}}\right) & =\sigma_{\eta}^{2}, \\
\operatorname{plim} \frac{1}{n} \sum_{i}\left(\tilde{w}_{i c s}-\overline{\tilde{w}}\right)\left(w_{c s}-\bar{w}\right) & =\sigma_{\eta}^{2}+\frac{\sigma_{v}^{2}}{\bar{N}-1} .
\end{aligned}
$$


Substituting (A1) into (A2), taking the plim, and rearranging yields

$$
\begin{aligned}
& \hat{\beta}_{\mathrm{OLS}}= \frac{1}{n} \sum(\tilde{w}-\tilde{\tilde{w}})^{2} \frac{1}{n} \sum[\beta(X-\bar{X})+\lambda(w-\bar{w})+(\epsilon-\bar{\epsilon})](\tilde{X}-\bar{X}) \\
& \frac{1}{n} \sum(\tilde{X}-\bar{X})^{2} \frac{1}{n} \sum(\tilde{w}-\overline{\tilde{w}})^{2}-\left[\frac{1}{n} \sum(\tilde{w}-\overline{\tilde{w}})(\tilde{X}-\bar{X})\right]^{2} \\
&-\frac{\frac{1}{n} \sum(\tilde{w}-\overline{\tilde{w}})(\tilde{X}-\bar{X}) \frac{1}{n} \sum[\beta(X-\bar{X})+\lambda(w-\bar{w})+(\epsilon-\bar{\epsilon})](\tilde{w}-\tilde{\tilde{w}})}{\frac{1}{n} \sum(\tilde{X}-\bar{X})^{2} \frac{1}{n} \sum(\tilde{w}-\overline{\tilde{w}})^{2}-\left[\frac{1}{n} \sum(\tilde{w}-\overline{\tilde{w}})(\tilde{X}-\tilde{X})\right]^{2}}, \\
& \operatorname{plim} \hat{\beta}_{\mathrm{OLS}}=\frac{\left(\sigma_{\eta}^{2}+\frac{\sigma_{v}^{2}}{\bar{n}-1}+\frac{\sigma_{u}^{2}}{\bar{n}-1}\right)\left(\beta \sigma_{X}^{2}+\lambda \sigma_{\eta}^{2}\right)-\sigma_{\eta}^{2}\left[\beta \sigma_{\eta}^{2}+\lambda\left(\sigma_{\eta}^{2}+\frac{\sigma_{v}^{2}}{\bar{N}-1}\right)\right]}{\left(\sigma_{\eta}^{2}+\frac{\sigma_{v}^{2}}{\bar{n}-1}+\frac{\sigma_{u}^{2}}{\bar{n}-1}\right)\left(\sigma_{\eta}^{2}+\sigma_{v}^{2}+\sigma_{u}^{2}\right)-\sigma_{\eta}^{4}} \\
&= \beta \frac{\sigma_{v}^{2}\left(\sigma_{v}^{2}+\sigma_{u}^{2}\right)+\sigma_{\eta}^{2}\left(\bar{n} \sigma_{v}^{2}+\sigma_{u}^{2}\right)}{\sigma_{v}^{2}\left(\sigma_{v}^{2}+\sigma_{u}^{2}\right)+\sigma_{\eta}^{2}\left(\bar{n} \sigma_{v}^{2}+\sigma_{u}^{2}\right)+\sigma_{u}^{2}\left[(\bar{n}-1) \sigma_{\eta}^{2}+\sigma_{v}^{2}+\sigma_{u}^{2}\right]} \\
&+\lambda \frac{\sigma_{\eta}^{2}\left(\frac{\bar{N}-\bar{n}}{\bar{N}-1} \sigma_{v}^{2}+\sigma_{u}^{2}\right)}{\left(\sigma_{v}^{2}+\sigma_{u}^{2}\right)\left(\bar{n} \sigma_{\eta}^{2}+\sigma_{v}^{2}+\sigma_{u}^{2}\right)} .
\end{aligned}
$$

In order to study the within-class estimator $\hat{\beta}_{W}$, consider the deviations from class means

$$
\begin{aligned}
& X_{i c s}-\bar{X}_{c s}=v_{i c s}-\bar{v}_{c s}, \\
& \tilde{X}_{i c s}-\overline{\tilde{X}}_{c s}=v_{i c s}-\bar{v}_{c s}+u_{i c s}-\bar{u}_{c s},
\end{aligned}
$$

with analogous transformations for $w_{i c s}$ and $\tilde{w}_{i c s}$ and for equation (A1). The plims are now taken with $C \rightarrow \infty$, where $C$ is the number of classrooms in the sample, with $n_{c s}$ and $N_{c s}$ fixed. The plims of the sample variance and covariance terms will be as above with two changes. First, the within transformation eliminates $\eta_{c s}$; hence the plims for the within variables will correspond to the case with $\sigma_{\eta}^{2}=0$. Second, the within variance and covariance terms have a small-sample bias of $(\bar{n}-1) / \bar{n}$ because classes are small and class sizes fixed. However, when we consider plim $\hat{\beta}_{W}$, this bias affects the numerator and denominator proportionately, so that we can obtain plim $\hat{\beta}_{W}$ simply from plim $\hat{\beta}_{\text {OLS }}$ by setting $\sigma_{\eta}^{2}=0$ :

$$
\operatorname{plim} \hat{\beta}_{W}=\beta \frac{\sigma_{v}^{2}}{\sigma_{v}^{2}+\sigma_{u}^{2}} .
$$


This is the standard attenuation bias from measurement error.

By a similar argument we obtain for $\hat{\lambda}$

$$
\begin{aligned}
\operatorname{plim} \hat{\lambda}_{\mathrm{OLS}}= & \beta \frac{(\bar{n}-1) \sigma_{u}^{2} \sigma_{\eta}^{2}}{\left(\sigma_{v}^{2}+\sigma_{u}^{2}\right)\left(\bar{n} \sigma_{\eta}^{2}+\sigma_{v}^{2}+\sigma_{u}^{2}\right)} \\
& +\lambda \frac{\left(\frac{\bar{n}-1}{\bar{N}-1}\right) \sigma_{v}^{2}\left(\sigma_{\eta}^{2}+\sigma_{v}^{2}+\sigma_{u}^{2}\right)+(\bar{n}-1) \sigma_{\eta}^{2}\left(\sigma_{v}^{2}+\sigma_{u}^{2}\right)}{\left(\sigma_{v}^{2}+\sigma_{u}^{2}\right)\left(\bar{n} \sigma_{\eta}^{2}+\sigma_{v}^{2}+\sigma_{u}^{2}\right)}, \\
\operatorname{plim} \hat{\lambda}_{W}= & \lambda\left(\frac{\bar{n}-1}{\bar{N}-1}\right) \frac{\sigma_{v}^{2}}{\sigma_{v}^{2}+\sigma_{u}^{2}} .
\end{aligned}
$$

We now turn to the IV estimator. The instruments

$$
\begin{aligned}
& z_{1 i c s}=X_{i c s}+u_{1 i c s}, \\
& z_{2 c s}=\bar{z}_{1 c s}=\eta_{c s}+\bar{v}_{c s}+\bar{u}_{1 c s}
\end{aligned}
$$

are based on an independent measurement of $X_{i c}$; that is, we assume $\operatorname{Cov}\left(u_{i c s}, u_{1 i c s}\right)=0$. Similar derivations as before imply

$$
\begin{aligned}
\operatorname{plim} \hat{\beta}_{\mathrm{IV}} & =\beta+\lambda\left(\frac{\bar{N}-\bar{n}}{\bar{N}-1}\right) \frac{\sigma_{\eta}^{2}}{\bar{n} \sigma_{\eta}^{2}+\sigma_{v}^{2}}, \\
\operatorname{plim} \hat{\beta}_{\mathrm{IV}, W} & =\beta, \\
\operatorname{plim} \hat{\lambda}_{\mathrm{IV}} & =\lambda\left(\frac{\bar{n}-1}{\bar{N}-1}\right) \frac{\bar{N} \sigma_{\eta}^{2}+\sigma_{v}^{2}}{\bar{n} \sigma_{\eta}^{2}+\sigma_{v}^{2}}, \\
\operatorname{plim} \hat{\lambda}_{\mathrm{IV}, W} & =\lambda\left(\frac{\bar{n}-1}{\bar{N}-1}\right) .
\end{aligned}
$$

\section{References}

Altonji, Joseph. 1988. The effect of family background and school characteristics on education and labor market outcomes. Unpublished manuscript, Department of Economics, Northwestern University.

Ammermueller, Andreas. 2005. Educational opportunities and the role of institutions. Discussion Paper no. 05-44, Zentrum für Europäische Wirtschaftsforschung, Mannheim, Germany.

Ashenfelter, Orley, and Alan Krueger. 1994. Estimates of the economic return to schooling from a new sample of twins. American Economic Review 84:1157-73. 
Boozer, Michael, and Stephen E. Cacciola. 2001. Inside the "black box" of Project STAR: Estimation of peer effects using experimental data. Discussion Paper no. 832, Economic Growth Center, Yale University.

Campbell, Jay R., Dana L. Kelly, Ina V. S. Mullis, Michael O. Martin, and Marian Sainsbury. 2001. Framework and specification for PIRLS assessment 2001. Chestnut Hill, MA: International Study Center, Lynch School of Education, Boston College.

Clotfelter, Charles T., Helen F. Ladd, and Jacob L. Vigdor. 2006. Teacherstudent matching and the assessment of teacher effectiveness. Journal of Human Resources 41:778-820.

Cullen, Julie Berry, Brian A. Jacob, and Steven Levitt. 2006. The effect of school choice on participants: Evidence from randomized lotteries. Econometrica 74:1191-1230.

DeGroot, Morris. 1984. Probability and statistics. 2nd ed. Reading, MA: Addison-Wesley.

Glewwe, Paul. 1997. Estimating the impact of peer group effects on socioeconomic outcomes: Does the distribution of peer group characteristics matter? Economics of Education Review 16:39-43.

Gould, Eric D., Victor Lavy, and M. Daniele Paserman. Forthcoming. Does immigration affect the long-term educational outcomes of natives? Quasi-experimental evidence. Economic Journal.

Graham, Bryan S. 2008. Identifying social interactions through conditional variance restrictions. Econometrica 76:643-60.

Hanushek, Eric A., John F. Kain, Jacob M. Markman, and Steven G. Rivkin. 2003. Does peer ability affect student achievement? Journal of Applied Econometrics 18:527-44.

Hoxby, Caroline. 2000. Peer effects in the classroom: Learning from gender and race variation. Working Paper no. 7867, National Bureau of Economic Research, Cambridge, MA.

Kane, Thomas J., Cecilia E. Rouse, and Douglas Staiger. 1999. Estimating returns to schooling when schooling is misreported. Working Paper no. 7235, National Bureau of Economic Research, Cambridge, MA.

Krueger, Alan B. 1999. Experimental estimates of education production functions. Quarterly Journal of Economics 114:497-532.

Manski, Charles F. 1993. Identification of endogenous social effects: The reflection problem. Review of Economic Studies 60:531-42.

McEwan, Patrick J. 2003. Peer effects on student achievement: Evidence from Chile. Economics of Education Review 22:131-41.

Mislevy, Robert. 1991. Randomization-based inference about latent variables from complex samples. Psychometrika 56:177-96.

Mullis, Ina V. S., Michael O. Martin, Eugenio J. Gonzalez, and Ann M. Kennedy. 2003. PIRLS 2001 international report: IEA's study of reading literacy achievement in primary schools. Chestnut Hill, MA: International Study Center, Lynch School of Education, Boston College. 
Mullis, Ina V. S., Michael O. Martin, Ann M. Kennedy, and Cheryl L. Flaherty. 2002. PIRLS 2001 encyclopedia: A reference guide to reading education in the countries participating in IEA's Progress in International Reading Literacy Study (PIRLS). Chestnut Hill, MA: International Study Center, Lynch School of Education, Boston College.

Schindler Rangvid, Beatrice. 2007. School composition effects in Denmark: Quantile regression evidence from PISA 2000. Empirical Economics 33:359-88.

Schneeweis, Nicole, and Rudolf Winter-Ebmer. 2007. Peer effects in Austrian schools. Empirical Economics 32:387-409.

Sojourner, Aaron. 2008. Inference on peer effects with missing peer data: Evidence from Project STAR. Unpublished manuscript, Department of Economics, Northwestern University.

Vigdor, Jacob L., and Thomas Nechyba. 2004. Peer effects in elementary school: Learning from "apparent" random assignment. Unpublished manuscript, Department of Economics, Duke University.

- 2006. Peer effects in North Carolina public schools. In Schools and the equal opportunities problem, ed. Ludger Woessmann and Paul E. Peterson. Cambridge, MA: MIT Press.

Wößmann, Ludger. 2008. How equal are educational opportunities? Family background and student achievement in Europe and the United States. Zeitschrift für Betriebswirtschaft 78:45-70. 